\title{
GARD, a new way to battle with chronic respiratory diseases, from disease oriented programmes to global partnership
}

\author{
Nikolai Khaltaev \\ Global Alliance against Chronic Respiratory Diseases, Geneva, Switzerland \\ Correspondence to: Nikolai Khaltaev, MD, PhD. Global Alliance against Chronic Respiratory Diseases, Geneva, Switzerland. \\ Email: khaltaevn@bluewin.ch.
}

\begin{abstract}
Initiated by World Health Organization (WHO) Global Chronic Respiratory Disease (CRD)oriented programmes, Global Initiative on Asthma (GINA), GOLD—Global Initiative for Chronic Obstructive Pulmonary Disease (COPD), Allergic Rhinitis and its Impact on Asthma (ARIA), and Practical Approach to Lung Health (PAL) have catalyzed creation of the Global Alliance Against CRD (GARD). Forty-five countries sharing GARD's goal to reduce the burden of CRD joint GARD. In 20 countries with reliable death estimates, CRD mortality has been analyzed in 2000, 2005, 2010 and 2015. Dramatic decline in CRD mortality is seen in Kyrgyzstan, Netherlands, Italy and Republic of Korea (69\%, 55\%, 48\%, and $48 \%$ ). Positive trend in COPD mortality is seen for Lithuania (36\% decline) and Spain (21\%). In France, Japan, Mexico, Romania and Costa Rica, positive trend for asthma mortality is obvious from 2000 to 2015 from about 40\% in France and Romania, 50\% and Mexico and Czech Republic, 65\% in Japan and 69\% in Belgium. In Costa Rica zero asthma mortality was registered in 2015. In Czechia and Belgium decline is seen from 2000 to 2005, which then stabilized in Czech Republic and went further down in Belgium. In Finland initially, low asthma mortality remains practically unchanged with slight decline in 2015 . In other countries analyzed, we did not see any positive trend in CRD mortality. In all countries with positive CRD dynamic WHO introduced activities remained active, they have been taken into local guidelines and practice and supported national authorities in implementing these evidence-based guidelines. Before GARD launch WHO initiated activities produced a good basis for further GARD movement and by 2010 we see a visible positive trend in CRD mortality in success countries. By 2015 when WHO noncommunicable disease (NCD) Global Action Plan 2013-2020 rollouts globally dramatic decline in total CRD mortality and particularly in Asthma and COPD mortality became obvious. Global disease oriented programmes, national and international partnerships combined with the Global NCD Action Plan most probable produce a positive synergistic effect on the mortality from CRD.
\end{abstract}

Keywords: Asthma; chronic obstructive pulmonary disease (COPD); allergy; World Health Organization (WHO); Global Alliance Against Chronic Respiratory Disease (GARD)

Submitted Sep 18, 2017. Accepted for publication Oct 30, 2017.

doi: $10.21037 /$ jtd.2017.11.91

View this article at: http://dx.doi.org/10.21037/jtd.2017.11.91

\section{Introduction}

Despite enormous burden and 4 million annual deaths caused by chronic respiratory diseases (CRD) (1), World Health Organization (WHO) CRD programme has a fairly short history within WHO established in 1948. Comparatively with well recognized cardiovascular disease (CVD), cancer or diabetes programmes, CRD were underrecognized and underestimated. As part of other noncommunicable diseases programme mainly focused on diabetes, CRD were neglected for many years being a component of tobacco initiative [prevention of chronic obstructive pulmonary disease (COPD)] or immunology programme (standardization of vaccines).

In 1988 jointly with the International Union against 
Tuberculosis and Lung Diseases, WHO has organized a meeting on future research needs relating to epidemiology of chronic airways disease (CAD). The purpose of the meeting was to make estimates of the magnitude of the problem, identify its etiologic factors and introduce strategies to prevent and control CAD (2).

Three years later WHO and US based National Heart Lung and Blood Institute convened a series of workshops on the development of "Global Strategy for Asthma Management and Prevention" with participants from all WHO regions. In March 1993, WHO then convened the workshop members into a study group to document information on the nature and extent of asthma worldwide and to recommend appropriate approaches to its prevention and control. As an outcome of this study group Global Initiative on Asthma (GINA) has become first global CRD programme where workshop participants played a key role in promoting asthma programme in all WHO regions (3). To disseminate GINA recommendations worldwide WHO took part in the annual World Asthma Day 5th May.

COPD as a major public health problem fails to receive adequate attention from the health care community and government officials. To increase awareness of COPD WHO and NHLBI in 1998 convened a joint meeting preceded by a series of workshops. Consensus report "Global strategy for the diagnosis, management, and prevention of COPD" was prepared by a distinguished multidisciplinary group of experts. Members of the workshop transformed into the "Global Initiative for COPD" (GOLD) became its key players. GOLD had to bring COPD to the attention of governments, public health officials, health care workers and the general public assuming that concerted efforts by all involved in health care will be necessary to control this mayor public health problem (4), WHO then presented the perspectives on the epidemiology, and control of COPD in the developing countries (5). The GOLD dissemination committee through a network of GOLD national leaders, scientific societies and patients groups conducts World COPD Day usually held 17 th November.

It has been estimated by that time that over $20 \%$ of the world population suffers from IgE-mediated allergic diseases such as allergic asthma, allergic rhinitis and allergic conjunctivitis, atopic eczema/atopic dermatitis and anaphylaxis. Since asthma in more than $50 \%$ adults and at least in $80 \%$ of affected children is allergic (6) and allergic rhinitis was considered as a risk factor for asthma along with other known risk factors $(7,8)$ it was decided to integrate allergic rhinitis into current WHO initiatives. WHO
Meeting on Allergic Rhinitis and its Impact on Asthma was convened in Geneva in 1999 (9). Meeting participants have formed a new global initiative called ARIA (Allergic Rhinitis and its Impact on Asthma). Renowned experts from all WHO regions became focal points for global promotion and implementation of ARIA. ARIA mission was to educate and implement existing evidence-based knowledge on allergic rhinitis in conjunction with asthma worldwide to improve the health of broad sector of the population, setting up rural health care activities, providing support for prevention, diagnosis and therapeutic measures as part of basic health care.

Thinking about implementation of the global initiatives in countries it was obvious that only Ministries of Health $(\mathrm{MOH})$ could successfully bring together different experts and national leaders to overcome existing barriers and strengthen national partnership. To assist countries with this integration and implementation of above mentioned activities WHO strategy for prevention and control of CRD was developed (10). The goal of the strategy was to support Member States in their efforts to reduce the toll of morbidity, disability and premature mortality related to CRD. Taking into account high burden of CRD in developing countries WHO organized a series of meetings on implementation of the strategy in low- and middleincome African countries (11) where WHO called to overcome existing barriers and strengthen national and international partnerships. This was along the lines of the 53 World Health Assembly (WHA) resolution which recognized CRD as a priority noncommunicable disease (NCD) together with CVD, cancer and diabetes mellitus to be addressed. The WHA requested the Director General:

* To continue giving priority to prevention and control of NCD including CRD with special emphasis on developing countries and other deprived populations;

* To strengthen existing partnerships and develop new ones, notably with specialized national and international nongovernmental organizations (NGO), with a view to sharing responsibilities for implementation of the global strategy based on each partner's experience;

* To coordinate, in collaboration with the international community, global partnership and alliances for resource mobilization, advocacy, capacity building and collaborative research (WHA resolution 53.17 May 2000).

Keeping in mind that tuberculosis (TB) a major lung disease has high prevalence in low income countries in 
deprived populations and commonality of TB symptoms with major chronic noncommunicable respiratory diseases WHO CRD programme joint Practical Approach to Lung Health (PAL) initiative launched by WHO TB programme (12). PAL is a syndromic approach to the management of patients who attend primary health care (PHC) services for respiratory symptoms. It's an integrated health care service package targeting 20-30\% of patients aged 5 years and above, such as TB, acute respiratory infection with a focus on pneumonia, asthma, and COPD. The PAL strategy is directed to multipurpose health workers, nurses, doctors and managers in PHC settings with successful TB control programmes in low- and middle-income countries.

Following the WHA resolution and having all set of tools as global initiatives (GINA, GOLD, ARIA, and PAL) and understanding the need of coordinated international partnership WHO convened the consultation of experts from 17 governmental and nongovernmental organizations on prevention and control of CRD at country level "towards a Global Alliance Against Chronic Respiratory Diseases (GARD)" (13).

Two years later in Beijing, GARD has been officially launched. Representatives of 41 organizations, institutions and agencies focused on reducing the global burden of CRD and individual experts met to define and agree GARD goal, purpose and expected results and to define and agree the role that each participant could have achieving GARD goal (14).

\section{Background}

The GARD is an alliance of national and international organizations, medical and scientific societies, institutions and agencies all working with the common goal of reducing the global burden of CRD (15). WHO provides technical leadership and secretariat support. The vision of GARD is a world where all people breathe freely. Its goal is to reduce the global burden of CRD, and its purpose is to initiate a comprehensive approach to fight CRD in countries. To achieve this goal GARD has set out four strategic objectives:

(I) Advocacy. To raise the recognition of the importance of CRD at global and country levels, and to advocate integration of the prevention and control of such diseases into policies across all government departments;

(II) Partnership. To promote partnering for the prevention and control of CRD;
(III) National plans on prevention and control. To support $\mathrm{WHO}$ in assisting countries to establish and strengthen national policies and plans for the prevention and control of CRD using WHO endorsed approaches and methods;

(IV) Surveillance. To support WHO in monitoring CRD and their determinants and to evaluate progress at country, regional and global levels.

More than 90 organizations and 45 countries expressed an interest to be involved in GARD development and adopt the GARD approach. The GARD Action Plan 2008-2013 (16) has become an instrument of the NCD Action Plan 2008-2013 calling to work in partnership to prevent and control major NCD-CVD, diabetes, cancers and CRD (17). In order for the activities of the Global Alliance to meet specific needs of countries, national alliances (GARD countries) have been established with a view to provide a coordination role and create the necessary momentum to strengthen the national capacity to face the increasing impact of CRD. MOH becomes GARD focal point liaising with WHO and GARD countries (partnerships of national NGO, patient organizations, professional societies, universities, hospitals, international NGO involved in community based intervention, private sector, multinational cooperative agencies, etc.) through National GARD coordinator. The WHO as GARD partner provides technical leadership and secretarial support for the Alliance. GARD strategy, GARD international and national activities have been well described during the years after GARD launch (18) WHO/GARD activities could be relatively divided to activities before United Nations High-level Meeting on NCD and Adoption of Political Declaration on the Prevention and Control of NCD 2011 (19) and after the meeting when GARD activities have become a part of global NCD movement inspired by the UN which recognized NCD as the leading cause of death worldwide, accounting for half of all global disability, including blindness and amputations, imposing huge costs on families, healthcare systems, business and national economies. The burden is rising everywhere due to changing patterns in the way we live and work. The greatest increase will be in low-and middle-income countries, contributing to poverty and becoming a major barrier to development. NCD were considered as a priority within the development agenda and $\mathrm{WHO}$ was assigned to coordinate global action on NCD along with the whole-of-government approach to implement WHO's recommendations on surveillance, prevention and health care. 
After adoption of the Declaration WHO has developed Global NCD Action Plan 2013-2020 (20) which has operationalized the commitments of the Political Declaration. The action plan provides a road map for the global community, to act in a coordinated and coherent manner. It is a means of implementing the global monitoring framework to attain the nine voluntary global targets, including the target on premature mortality of a $25 \%$ relative reduction in overall mortality from CVD, cancer, diabetes and CRD by 2025 .

GARD strategic objectives became well corresponding and complementing global NCD strategic objectives: to raise priority to NCD through cooperation and advocacy, to strengthen national capacity, leadership, governance, multi-sectoral action and partnerships, to reduce risk factors for NCD, to strengthen and orient health systems to address the prevention and control of NCD and its social determinants through $\mathrm{PHC}$, to promote and support national capacity for high quality research, and to monitor trends of NCD. A special analysis is needed to evaluate GARD contribution to the total NCD Action Plan, which was not a purpose of this article and from the view point of country benefit has only perceiving sense.

\section{Methods}

By the year 2008 GARD has been officially launched or initiated in the following 24 low- and middle-income countries: Algeria, Bangladesh, Brazil, Bulgaria, Cape Verde, China, Costa Rica, Egypt, Georgia, India, Islamic Republic of Iran, Kazakhstan, Kyrgyzstan, Mexico, Morocco, Pakistan, Paraguay, the Philippines, Romania, South Africa, Tunisia, Turkey, Viet Nam and the Republic of Zambia, and 21 high-income countries: Argentina, Canada, Chile, Czech Republic, Denmark, Finland, France, Greece, Italy, Japan, Lithuania, Netherlands, Norway, Poland, Portugal, the Republic of Korea, the Russian Federation, Spain, the United Arab Emirates, the United Kingdom and the USA. Argentina, Chile and Lithuania were middle-income countries when GARD was started.

To make assessment of CRD mortality in GARD countries after launch of GARD and before appearance of the UN Political Declaration and Adoption of WHO Global NCD Acton Plan (20) we choose countries where activities well responded to the needs of those countries and were conducted by the governments and supported by GARD (21). For the analysis we used WHO NCD country profiles in 2008 and $2012(22,23)$ highlighting the status of NCD in each WHO member state. This document provides an updated overview of the situation with NCD, including CRD, related to their mortality, risk factors and national systems capacity to prevent and control NCD. The profiles include the number, rates and causes of deaths from NCD (CRD), trends in NCD mortality since 2000 to 2012, prevalence of selected risk factors, and information describing current national responses to prevention and control of NCD. To see association between GARD country activities and mortality from CRD we have compared proportional CRD mortality in 2008 and 2012 for: Brazil, Chile, Finland, Kyrgyzstan, Republic of Korea, Russia, Portugal, Italy and Netherlands (Table 1). Countries with high degree of uncertainty because age-adjusted mortality data where not based on any national NCD mortality data have not been included in the analysis of NCD country profiles. We did not analyze CRD mortality trends presented in the NCD profiles from 2000 to 2012 because data there were presented for all CRD (23). We did it for the assessments until 2015 (Tables 2,3) where along with total CRD mortality data for COPD, Asthma and other CRD were presented. To better see associations of the disease-oriented and allied activities with CRD mortality in selected GARD countries and assuming great impact of the Global NCD Action Plan on the Health Estimates we used for this purpose four death estimations 2000, 2005, 2010 and 2015 (24).

Out of 33 countries (25) maintaining contacts with WHO GARD secretariat CRD mortality has been analyzed in 20 countries: Belgium, Canada, Chile, Costa Rica, Czech Republic, Denmark, Finland, France, Italy, Japan, Kyrgyzstan, Lithuania, Mexico, Netherlands, Norway, Republic of Korea, Romania, Spain, United Kingdom, and USA. Only data based on the multiple years of national death registration data with high completeness and quality of cause of death assignment were used in this analysis. Estimates for these countries may be compared and time series may be used for priority setting and policy evaluation (24).

\section{Results}

CRD mortality, tobacco smoking [2008-2011] health systems response, WHO initiated activities and anti-tobacco actions from 2008 to 2012 in selected GARD countries presented in Table 1.

CRD mortality varying from $2 \%$ to $6 \%$ declined from $6 \%$ to $4 \%$ only in Kyrgyzstan. It did not change in other countries. Total tobacco smoking either did 
Table 1 CRD mortality, tobacco smoking, national systems response and WHO initiated activities in selected GARD countries, 2008 and 2012

\begin{tabular}{|c|c|c|c|c|c|c|c|c|c|c|c|c|c|c|c|c|c|c|}
\hline \multirow{3}{*}{ Countries } & \multirow{2}{*}{\multicolumn{2}{|c|}{$\begin{array}{l}\text { Proportional CRD } \\
\text { mortality (\% of } \\
\text { total deaths, all } \\
\text { ages, both sexes) }\end{array}$}} & \multicolumn{6}{|c|}{ Current tobacco smoking (\%) } & \multirow{2}{*}{\multicolumn{2}{|c|}{$\begin{array}{l}\text { NCD unit in } \\
\text { the Ministry } \\
\text { of Health or } \\
\text { equivalent }\end{array}$}} & \multirow{2}{*}{\multicolumn{2}{|c|}{$\begin{array}{c}\text { NCD/CRD } \\
\text { national policy, } \\
\text { strategy or } \\
\text { actin plan }\end{array}$}} & \multirow{2}{*}{\multicolumn{2}{|c|}{$\begin{array}{l}\text { Policy strategy } \\
\text { or action plan } \\
\text { against } \\
\text { tobacco }\end{array}$}} & \multicolumn{4}{|c|}{$\begin{array}{l}\text { WHO initiated global } \\
\text { CRD activities }\end{array}$} \\
\hline & & & \multicolumn{2}{|c|}{ Males } & \multicolumn{2}{|c|}{ Females } & \multicolumn{2}{|c|}{ Total } & & & & & & & GINA & GOLD & ARIA & PAL \\
\hline & 2008 & 2012 & 2008 & 2011 & 20082 & 2011 & 2008 & 2011 & 2008 & 2012 & 2008 & 2012 & 2008 & 2012 & 1993 & 1998 & 1999 & 2004 \\
\hline Brazil & 6 & 6 & 17.3 & 22 & 11 & 13 & 14.1 & 17 & Yes & Yes & Yes & No & Yes & Yes & +++ & +++ & +++ & +++ \\
\hline Finland & 3 & 3 & 24.4 & 27 & 15.8 & 20 & 20 & 24 & Yes & Yes & Yes & * & Yes & No & +++ & +++ & +++ & \\
\hline Italy & 5 & 5 & 26.3 & 31 & 13.5 & 18 & 19.6 & 25 & Yes & Yes & Yes & Yes & Yes & Yes & +++ & +++ & +++ & \\
\hline Kyrgyzstan & 6 & 4 & 38.2 & 45 & 1.3 & 2 & 19.2 & 23 & * & No & * & Yes & * & Yes & +++ & +++ & +++ & +++ \\
\hline Netherlands & 6 & 6 & 24.6 & 29 & 23.6 & 23 & 24.1 & 26 & Yes & Yes & No & No & Yes & No & +++ & +++ & +++ & \\
\hline Russia & 2 & 2 & 65.5 & 59 & 19.7 & 25 & 40.5 & 40 & Yes & Yes & Yes & Yes & Yes & Yes & +++ & +++ & +++ & + \\
\hline
\end{tabular}

*, no information; +++, supported by national authorities, taken into national guidelines; +, presented in the country, taken into local guidelines. GARD, Global Alliance against Chronic Respiratory Diseases; CRD, chronic respiratory disease; GINA, Global Initiative on Asthma; GOLD, Global Initiative for Chronic Obstructive Pulmonary Disease; ARIA, Allergic Rhinitis and its Impact on Asthma; PAL, Practical Approach to Lung Health; NCD, noncommunicable disease.

not change in Republic of Korea and Russia or even increased in other countries while anti-tobacco policies, programmes or strategies have been in place. In some countries anti-tobacco activities have been covered by integrated policy against NCD (Portugal, Kyrgyzstan). One of the achievements of GARD countries was creation in the MOHs of the operational NCD units/ branches or departments with national plans against major NCD/CRD. Governmental approach against tobacco consumption was in place in all countries. There is no question that GINA GOLD and ARIA have been taken into local guidelines and practice. PHC guidelines based on PAL have been used in middle income Chile $(26,27)$ and low-income Kyrgyzstan $(27)$. No doubt that all these initiatives had an association with positive changes in the CRD mortality, admission rate and National systems response to NCD/CRD. It was difficult to expect that within this fairly short period of time after GARD launch we shall see visible changes in the mortality rate in the majority of GARD countries. Gender fluctuation in tobacco smoking remains either practically unchanged or within about the same range, without big changes which could impact the mortality characteristics. The most important think was to demonstrate that GARD countries were functioning and GARD associated activities in countries went along the lines of national activities against NCD. National NCD/CRD policy/strategy or action plan were adopted in the majority of countries after launch. In Kyrgyzstan NCD unit was combined with TB department. National action plan for NCD/CRD have been adopted only in 2012. So other national diseaseoriented activities and programmes could be involved in the changes of CRD mortality seen in this country after GARD launch. In the Netherlands National CRD Action Plan was adopted in 2014. Dramatic decline in total CRD, COPD and Asthma mortality comparatively with the year 2000 is seen in Kyrgyzstan 69\%, Netherlands 55\%, Italy 48\%, and Republic of Korea $48 \%$ comparatively with the year 2015 (Table 2, Figure 1). Positive trend in COPD mortality is seen for Lithuania (36\% decline) and Spain (21\%) (Table 3, Figure 2) In France, Japan, Mexico, Romania and Costa Rica, positive trend for asthma mortality is obvious from 2000 to 2015 from about 40\% in France and Romania, $50 \%$ in Mexico and Czech Republic, 65\% in Japan and $69 \%$ in Belgium. In Costa Rica statistics has registered zero asthma mortality rates in 2015. In Czechia and Belgium decline is seen from 2000 to 2005 , which then stabilized in Czech Republic and went further down in Belgium. In Finland initially low asthma mortality $0,2 \%$ of total deaths remain practically unchanged with slight decline in 2015. 
Table 2 CRD deaths ('000) 2000-2015 in selected GARD countries, all ages, both sexes*

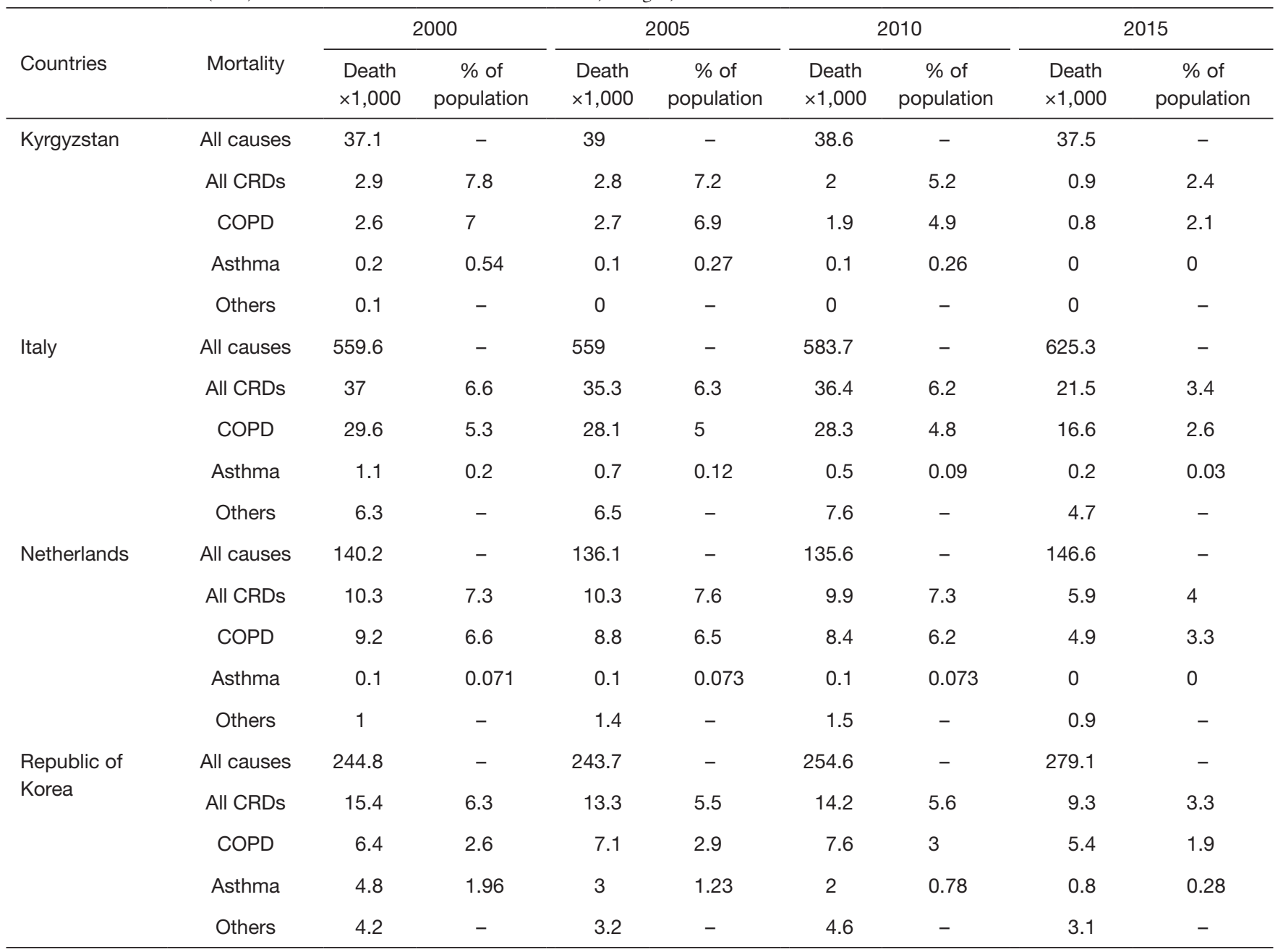

*, Global health estimates 2015. Health statistics and information systems estimates for 2000-2015. Geneva, WHO 2016 released March 2017 (24). '000 means multiplied by 1,000. GARD, Global Alliance against Chronic Respiratory Disease.

In other countries analyzed we did not see any positive dynamic in total CRD Asthma or COPD mortality. In Turkey (Prof A. Yorgancioglu), Portugal (Prof. J. Rosado Pinto), Brazil (Prof. P. Camargos and Dr. A. Cruz), South Africa (Prof. E. Bateman), Poland (Prof. T. Samolinski and Dr. P. Kuna), Vietnam (Dr. Lan Le Thi Tuyet) and many others countries excellent development of National GARD failed to be well analyzed due to statistical problems since deaths registration data there have low completeness and improvement in the registration systems may affect the estimated trends in cause-specific mortality. Dramatic decline of CRD mortality in China (Prof. Nanshan Zhong National GARD coordinator) was recommended to analyze with caution due to same reason. In some countries death registration data are unavailable or unusable due to quality issues.

\section{Discussion}

In all countries with positive CRD dynamic WHO introduced activities remained active. By the year 2000 GINA initiated in 1993 became a well-known and developed global programme was introduced in more than 80 countries. GOLD and ARIA have also appeared in all GARD countries. By 2005 all of them have been well functioning globally both in developed and developing countries. Although in some GARD countries there are no formal movements with their names there is no question 
Table 3 COPD and asthma mortality in selected GARD countries 2000-2015

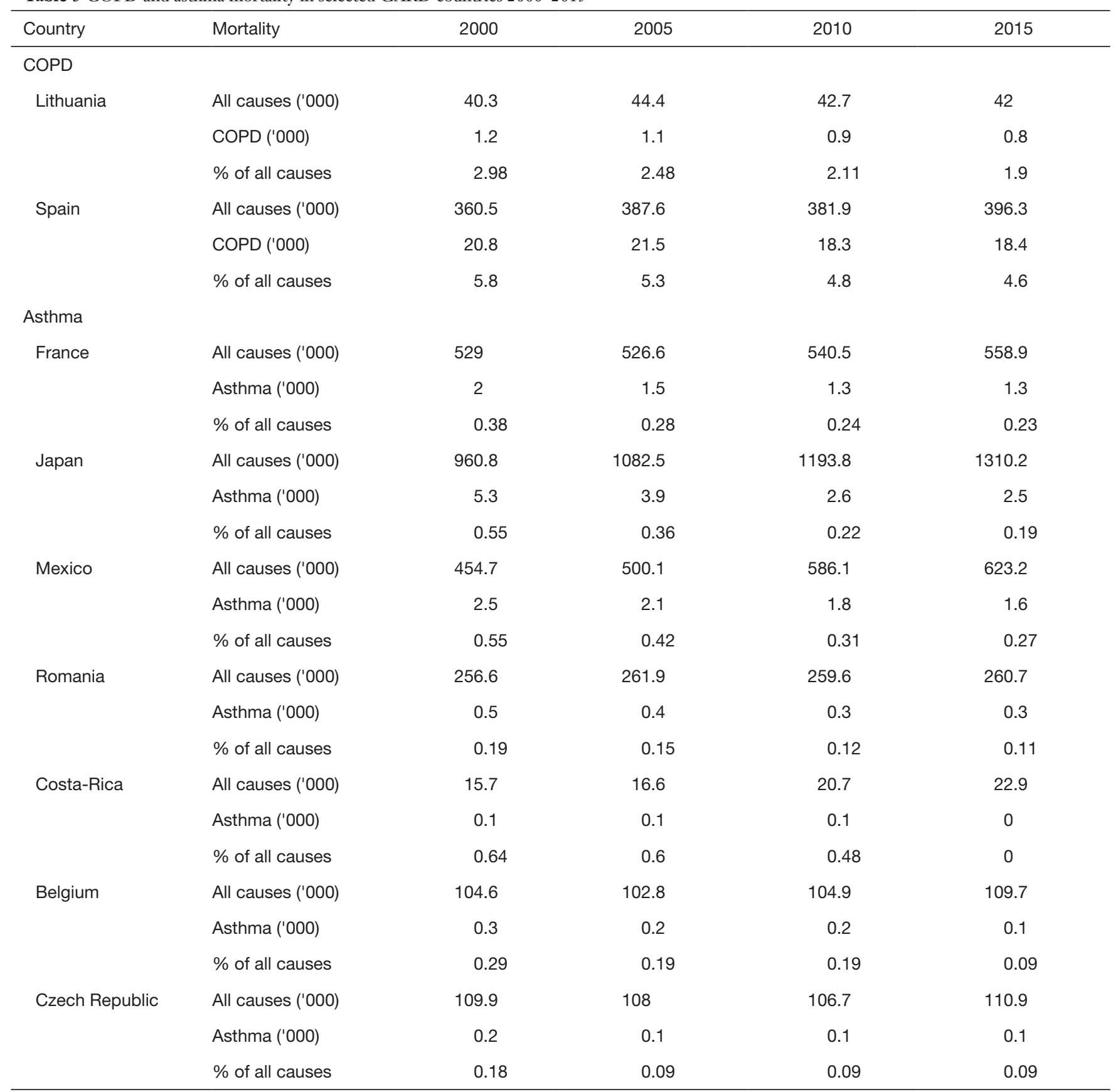

COPD, chronic obstructive pulmonary disease; GARD, Global Alliance against Chronic Respiratory Disease. '000 means multiplied by 1,000.

they have been taken into local guidelines and practice and supported national authorities in implementing these evidence-based guidelines. PAL has been initiated in low income countries with successful TB control programme. Thus, before GARD launch WHO initiated activities produced a good basis for further GARD movement and by the year 2010 we see a visible positive trend in CRD mortality in Kyrgyzstan, Netherlands and Italy and asthma mortality in Korea (Figure 1). By 2015 WHO NCD Global Action Plan rollouts globally in all member states and we can see dramatic decline in total CRD mortality and particular in COPD mortality. Since $90 \%$ of CRD deaths 
Dynamics of CRD mortality in selected GARD countries 2000-2015
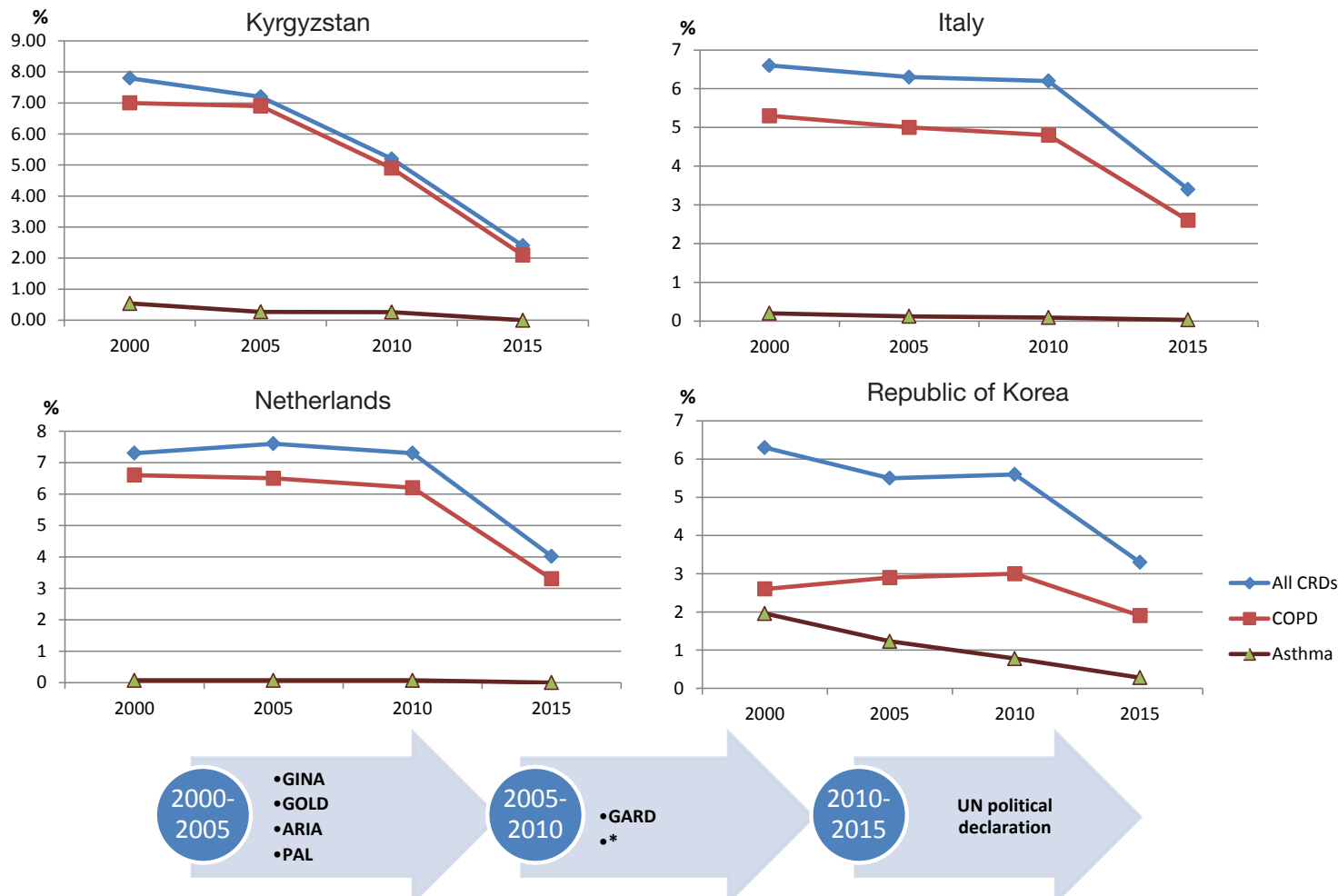

-GARD

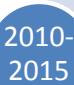

UN political

declaration

* Intergovernmental programme (Kyrgyzstan )

Figure 1 Dynamics of CRD mortality in selected GARD countries 2000-2015. CRD, chronic respiratory disease; GARD, Global Alliance against Chronic Respiratory Diseases.

COPD and ASTHMA mortality in selected GARD countries 2000-2015

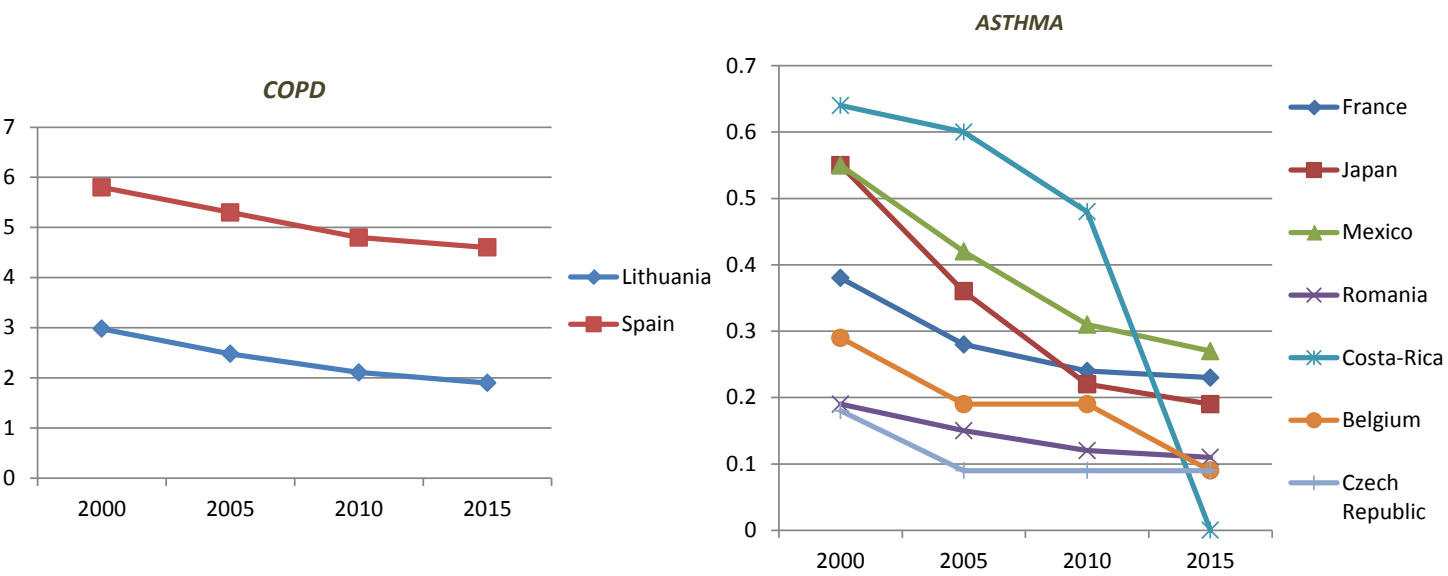

Figure 2 Trends of COPD and asthma mortality in selected GARD countries 2000-2015. COPD, chronic obstructive pulmonary disease; GARD, Global Alliance against Chronic Respiratory Diseases. 
occur in low- and middle-income countries (1) we have analyzed trends in CRD mortality in low income country Kyrgyzstan (Table 2, Figure 1).

Kyrgyzstan is a mountainous country where $35 \%$ population lives in urban areas. Kyrgyzstan had the highest CRD death rate in the European region [1996] especially among highlanders (28) before implementation of WHO initiatives. After National GARD launch in 2008 ageadjusted CRD mortality decreased from $6 \%$ to $4 \%$ in 2012 (Table 1) while the smoking rate increased from $38.2 \%$ to $45.1 \%$ in males and from $1.3 \%$ to $2 \%$ in females. However positive trend in CRD mortality began from 2000 and is associated with Kyrgyzstan-Finland Programme on Lung Health [2003-2007] based on the intergovernmental agreement signed in 2002. Active GARD members FILHA (Finnish Lung Health Association) and PAL Kyrgyzstan effectively implemented joint lung health programme. This country wide comprehensive programme was focused on respiratory diseases and tuberculosis. The goal of the project was to reduce mortality and morbidity from respiratory diseases through better prevention, diagnosis and treatment at the PHC level. To achieve this goal, national policy on respiratory diseases have been developed and approved. Broad educational campaign was run. A total of 3,544 medical professionals have been trained. All received the minimal set of equipment needed for diagnosis of respiratory diseases. Seven pulmonology departments received all necessary equipment. Eighty thousand copies of different lung health promotional materials were published and a series of anti-tobacco laws have been signed by the president of the republic. This strong governmental commitment had no doubt positive impact on lung health in the republic before GARD launch in 2008. After the launch GARD leaders and WHO staff regularly visited Kyrgyzstan to promote further lung health programme and strengthen existing partnership to implement national CRD programme. Twelve partners and 5 interested parties work together on implementation of the programme among them FILHA, PAL, extended Kyrgyz-Finish Lung Health project [2007-2010], Brazilian MOH on management of CRD in low resource settings. GARD Netherland and GARD member IPCRG (International Primary Care Respiratory Group) collaborate with GARD Kyrgyzstan on Fresh Air programme (Free Respiratory Evaluation and Smokeexposure reduction by Primary Health Care Integrated Groups) in population which lives at 2,200-3,200 meters above the sea level and is continuously affected by negative extreme conditions (exogenous hypoxia, cold, strong winds, low humidity) and indoor air pollutants caused by the use of biomasses for heating homes and cooking as well as high smoking rate).Smoking prevalence in Kyrgyzstan continue increasing to $50.5 \%$ in males $3.7 \%$ in females and 26.5 for both sexes (29) comparatively with previous estimates in 2008 and 2011 (22,23). This study along with anti-tobacco law ratified in 2006 will further improve the lung health of the nation. GARD Kyrgyzstan (National GARD coordinator Prof. T. Sooronbaev) has become one of the key initiators and the participants of the National NCD/CRD Programs in close cooperation with the WHO country office.

GARD-Italy was set up in June 2009. It consists of 42 members (21). The MOH offers technical leadership and the secretariat. The mission and intent of GARD Italy are indicated in a strategy paper prepared by the $\mathrm{MOH}$ in collaboration with the scientific societies and patient associations in the area of respiratory disease (30). Each member of GARD Italy accepts the strategy document and goals of the Alliance. The specific objectives are the following: (I) to build partnerships; (II) to create a database for respiratory diseases; (III) to advocate for action against CRDs; (IV) to foster the implementation of policies for health promotion and prevention of respiratory disease; $(\mathrm{V})$ to foster the implementation of strategies for management of CRD; (VI) to foster inter-sectoral collaboration. GARD Italy has set up its own rules of procedures, and is divided into General Assembly and Executive Committee, and operates through working groups. Italy represents a real opportunity for developing a comprehensive strategy for prevention and care of respiratory disease adapted to the national context. The objectives can be achieved only if fragmentation and lack of coordination can be avoided. The Alliance accepts the challenge for the NCD global strategy. To promote GARD in the EU during the Italian Presidency of the EU Council, GARD Italy and the $\mathrm{MOH}$ organized a regional GARD meeting in October 2015 in Rome. Prof. G. Viegi is National GARD coordinator; many of National GARD members have been involved in GINA, GOLD and ARIA initiatives. Anti-tobacco actions led to the introduction in 2012 of the ban on the sale of cigarettes to anyone under 18 years old, and the extension of the smoking ban to outdoor areas of schools. In recent years Italy has strengthened actions aimed at promoting healthy lifestyles by developing intersectoral strategies for health promotion and NCD prevention.

The Dutch National Action Program on Chronic Lung Diseases has been developed in collaboration between 
the Netherlands Lung Alliance (NLA), advised by Dr. N. Chavannes, National GARD coordinator, and the $\mathrm{MOH}$. The NLA with a network of 32 organizations aiming to reduce mortality from CRD and improve quality of life has presented the Dutch National Action Programme for Chronic Lung Diseases accepted by the $\mathrm{MOH}$. The Dutch Programme has five targets, from 2014 to 2018:

* $25 \%$ reduction in hospital days due to asthma and COPD;

* $15 \%$ reduction of lost working days due to asthma and COPD;

* $20 \%$ increase in efficiency of inhalation medication;

* $25 \%$ reduction in children below 18 years starting to smoke;

* $10 \%$ reduction in deaths due to asthma and COPD.

GARD Netherlands collaborates with Kyrgyzstan, Uganda and Greece through Fresh Air Programme. It collaborates with the Leiden University Medical Centre, IPCRG and several other institutions. Dutch experts have been very active in GINA, GOLD and ARIA since their beginning. GARD Netherlands National protocols for COPD and Asthma management include; inhalation protocols, PHC guidelines, guideline for palliative care of COPD, multidisciplinary guideline for asthma. At PHC patients receive a written action plan. Nurses, pharmacists and physiotherapists are involved in the delivery of care. Medicines for COPD and asthma are widely available for the whole population in PHC and affordable through healthcare insurance providers. The national GP organization organizes large scale training programmes in which 6,000 GPs have already participated.

In Republic of Korea where $83.2 \%$ population lives in urban areas, $56 \%$ of population are in the age $30-70$ years. UN Secretary General supported the efforts of GARD to combat the growing health crisis of CRD. $\mathrm{MOH}$ and Welfare and a network of 6 NGO in the area of respiratory and lung diseases are focused on the implementation of National programme against CRD. Korea Asthma and Allergy Foundation coordinate national activities through Dr. You Young Kim, National GARD coordinator. Taking into account increasing aging population and high prevalence of smoking in particular in males almost $50 \%$ in 2011 (23), Korean government is focused on the national programme on asthma and COPD in the elderly and tobacco regulation with Anti-Tobacco Act and increased the tobacco tax. GARD Korea supported this Act and coordinated a smoking ban campaign. These actions led to the visible decline in tobacco smoking prevalence in 2015 to $42 \%$ in males, $6.2 \%$ in females and to $23.9 \%$ for both sexes (29) comparatively with 2011 estimates $49 \%, 8 \%$ and $28 \%$ (Table 1) and are associated with dramatic decline in total and COPD mortality. WHO initiatives implemented in Korea before GARD launch in 2007 made a significant contribution to the development of National management guidelines and in particular in computer assisted asthma diagnosis and management programme by GARD Korea and Korea Centre for Disease Control. GARD Korea distributes the guidelines for prevention and control of CRD, conducts a nationwide survey for early detection and better control of patients, and undertakes health promoting campaigns and educational exhibitions.

In Spain and Lithuania, we observed gradual decline of COPD mortality (Table 3, Figure 2). Spain is characterized by high proportional mortality from of CRD 9\% (23). The Spanish Society of Pulmonology and Thoracic Surgery (SEPAR) estimates that more than 2 million people between 40 and 80 years of age suffer from COPD. This disease affects $10.2 \%$ of the adult population and 18,000 people die annually. COPD accounts for $40 \%$ of pulmonologist consultations and its diagnosis, management and treatment costs $2 \%$ of Spanish healthcare or 3,000 million Euros. SEPAR (President Dr. Inmaculada Alfageme), put additional efforts to train professionals in respiratory health to reduce underdiagnosis, and inform people about COPD highlighting the close relationship between tobacco and COPD. The Spanish COPD Guidelines used GOLD criteria and was developed by SEPAR together with the scientific societies involved in COPD patient care, and the Spanish Patient Forum (31).

Positive COPD dynamic in Lithuania (national coordinator Prof. A. Valiulis) besides the ongoing global CRD initiatives and National Systems Response could be also associated with country-wide community-based programmes on prevention of NCD initiated in the country in the 80 s when community-based CVD programmes expanded from CVD to NCD mainly because of the common risk factors (32). Community-based programmes, collaborated with all sectors of the community, and maintained close contacts with the national authorities for many years.

Positive dynamic of asthma mortality seen in France and Japan (Table 3, Figure 2) is associated with activities of WHO Collaborating Centres for CRD established in Montpellier (Prof. J. Bousquet) and Tokyo (Prof. S. Makino and Prof. H. Sagara) after launch of major WHO CRD initiatives. France remains a leading country in GARD francophone 
which was launched in 2007. This new coordination mechanism aims at grouping organizations, institutions and agencies to fight against the burden of CRD in francophone countries. GARD francophone remains active and facilitates the exchange of relevant information related to the burden of CRD in francophone countries. In addition, it works to increase awareness on the impact of lung diseases on people's health, and how they can be successfully prevented or treated. The burden of lung diseases in francophone countries is outstanding but it is clear that this epidemic can be controlled by well-coordinated efforts.

In Japan GARD works in close collaboration with the $\mathrm{MOH}$, Labor and Welfare on the National Plan for CRD focused on "Asthma Death Zero". Asthma prevention and control guideline and relevant protocols are being implemented nationally Patients receive a written action plan. At the PHC level feldshers and nurses are partially involved in the delivery of care where drugs for COPD and Asthma are available. GARD Japan supports CRD prevention and control activities in Mongolia, Cambodia and Laos.

Despite the low profile of CRD in National NCD activities GARD Romania (Dr. F. Mihaltan, Dr. R. Ulmeanu and Dr. D. Deleanu national coordinators) through the Romanian Society of Pulmonology (RSP) and the Romanian Society of Allergology regularly organizes meetings with family physicians, CRD conferences, symposiums, meetings to combat air pollution. It also organizes common health promoting activities with NGO. $\mathrm{MOH}$ and Chamber of Deputies control implementation of anti-tobacco law and activities organized by RSP. In particular anti-tobacco education in schools e-learning programmes, training of physicians, and journalists. Patients receive a written action plan. CRD are managed in PHC by physicians. Nurses are also involved in the delivery of care. Asthma management in $\mathrm{PHC}$ includes the involvement of patients to improve e- self management and adherence. The national GP organization organizes large-scale training programmes. GARD activities are monitored and reported at every GARD General Assembly Meeting.

GARD in Mexico (national coordinator Dr. S. N. Gonzales Dias) was born in Mexico City, in 2008 at the international workshop to discuss GARD. The event was organized by Dr. R. Perez Padilla, President of Latin American Thoracic Association active GARD member and initiator of GARD discussions in Mexico at the presence of high governmental officials, secretaries of Health, Mexico, and Mexico City. Secretary of Health, Mexico mentioned that CRD constitute a public health problem since the cost of this disease is very high and it will increase if no immediate action is taken. He supported GARD as an interesting strategy to involve different partners in a joint action against CRD. NCD operational unit in Mexico was established in the $\mathrm{MOH}$ and Action Plan against Tobacco was functioning in 2012 (23) along with long lasting GINA and ARIA initiatives.

In Belgium and Czech Republic GINA have very strong roots. Late Dr. Romain Pauwels and Dr. Vaclav Spicak have been members of first GINA panel (3) and made great efforts in introduction and implementation of GINA guidelines in their countries. Shortly after GINA launch a WHO Collaborating Centre for CRD has been designated in Ghent University (Director Prof. R. Pauwels, after his death in 2005 Prof. G. Joos). After official launch of GARD this Collaborating Centre and Ghent University joint GARD (Prof. G. Joos national GARD coordinator). In Czech Republic initiated by GINA GARD/Czechia became CARO (Czech Initiative against CRD, Dr. V. Kolek national coordinator) CARO launched with the support of $\mathrm{MOH}$ and WHO Country Office is very active in National awareness campaign on Healthy Lung and Asthma, World Asthma Day, World Spirometry Day. CARO is a strong player of good will lobbying for better air, stronger antismoking policy and rights of patients suffering from CRD.

GINA and ARIA have been introduced in Costa Rica by late Prof. Carlos Baena Cagnani. Proportional mortality from CRD was 6\% in 2008 and did not increase in 2012 remaining at the same level $6 \%$ while total NCD mortality increased from $81 \%$ in 2008 to $83 \%$ in 2012 $(22,23)$ Despite this fact CRD has low profile in the local NCD activities. There is no national CRD prevention and control programme or action plan. Positive dynamic of asthma mortality is associated with GINA and ARIA activities along with anti-tobacco law. Costa Rica signed Tobacco Free Initiative in 2003 which has been ratified in 2008. Prevalence of tobacco smoking in adults in 2011 was $24 \%$ for males, $8 \%$ for females and $16 \%$ for both sexes (23) which declined to $17.7 \%, 6.5 \%$ and $12.1 \%$ accordingly (29) Global CRD initiatives along with anti-tobacco actions are associated with dramatic decline of asthma mortality.

Practically stable level of asthma mortality in Finland is probably caused by long lasting CRD prevention programmes. Ten-year National Asthma Programme [1994-2004], where patients received special medication reimbursement based on physician-diagnosed asthma (33). and Finish Allergy Programme 2008-2018 (34), which like 
Asthma Programme has been initiated by Professor Tari Haahtela and became a GARD Demonstration Project (GARD national coordinator Dr. A. Nyberg). The Allergy Programme is an educational action plan, which takes the advantage of the contact person network created during the Asthma Programme. National collaborators/partners in the Allergy Programme are the Ministry of Social Affairs and Health, the National Public Health Institute, the Social Insurance Institution, the Finnish Institute of Occupational Health, the Associations of Finnish Pharmacies, FILHA, patient organizations, the Allergy and Asthma Federation and the Pulmonary Association. Like asthma and allergy programmes the 10-year National COPD programme 1998-2007 used GOLD approach and had a positive impact on burden of CRD in Finland (35).

\section{Conclusions}

In view of the huge global health burden of CRD and other major NCD there is a great need for international collaboration to diminish this disaster. Global disease - oriented programmes, national and international partnerships combined with the Global NCD Action Plan most probably produce a positive synergistic effect on the mortality from CRD. Practical networks with common guidelines but adaptable to local cultures in a flexible way have proved to be very useful interventions aimed at better management of CRD and modifying the levels of the major risk factors in the population. The systematic involvement of PHC centres can, in the long run, be one of the most effective intervention and maintenance tools in view of this the package of essential NCD interventions for PHC, WHO/PEN (36) is being implemented mainly in GARD low- and middle-income countries (Kyrgyzstan, Vietnam) since it is oriented to strengthen equitable and efficient $\mathrm{PHC}$ for NCD/CRD in low resource settings. It outlines a set of cost-effective interventions and considered as an important first step for integration of NCD into PHC and will further improve situation with CRD in GARD countries and globally.

Further extension of practical networks of GARD lowand middle-income countries sharing common PHC approaches and guidelines, will have significant impact on lung health in these countries. WHO's leadership in these networks is very valuable. In successful countries the success is associated with sustainable development of CRD initiatives, health systems response to growing CRD/NCD health problems, ability to forge collaborative partnership and development of shared vision with large number of partners like for instance in Italy.

In all success countries we have demonstrated the continuity of the WHO initiated CRD programmes which have catalyzed a global CRD partnership which preceded the UN Political Declaration on NCD and became a part of the Global NCD movement led by WHO. Positives dynamic of CRD mortality associated with our activities demonstrates that GARD is moving in the right direction. The Political Declaration on NCD, UN Sustainable Development Goals (37), and Global NCD Action Plan are significant achievements by the global community. GARD will build on these commitments and will continue working towards a world where all people breathe freely.

\section{Acknowledgements}

I would like to acknowledge Dr. Claude Lenfant and Dr. Suzanne Hurd with whom we initiated GINA and GOLD, Prof. Jean Bousquet Past President of GARD with whom we initiated ARIA.

\section{Footnote}

Conflicts of Interest: The author has no conflicts of interest to declare.

\section{References}

1. Global Status Report on Noncommunicable Diseases 2014. World Health Organization, 2014:298.

2. Woolcock AJ. Epidemiology of chronic airways disease. Chest 1989;96:302S-6S.

3. Global Initiative for Asthma. Global Strategy for Asthma Management and Prevention NHLBI/WHO Workshop Report. National Institutes of Health, National Heart, Lung, and Blood Institute, Publication Number 95-3659, 1995:176.

4. Global Initiative for Chronic Obstructive Lung Disease. Global Strategy for the Diagnosis, Management, and Prevention of Chronic Obstructive Pulmonary Disease. NHLBI/WHO Workshop Report. National Institute of Health, National Heart, Lung and Blood Institute, Publication Number 2701, 2001:100.

5. Khaltaev N. The Point of view of the WHO on Chronic Obstructive Pulmonary Disease. In: Similowski T, Whitelaw W, Derenne JP. Editors. Lung Biology in Health and Disease. New York: Marcel Dekker Inc., 
2002:1045-57.

6. Prevention of Allergy and Allergic Asthma. Based on the WHO/WAO Meeting on the Prevention of Allergy and Allergic Asthma, WHO/NMH/MNC/CRA/03.2, 2002:14.

7. Shaaban R, Zureik M, Soussan D, et al. Rhinitis and onset of asthma: a longitudinal population-based study. Lancet 2008;372:1049-57.

8. Cruz AA, Popov T, Pawankar R, et al. Common characteristics of upper and lower airways in rhinitis and asthma: ARIA update, in collaboration with GA(2)LEN. Allergy 2007;62 Suppl 84:1-41.

9. Bousquet J, van Cauwenberge P, Khaltaev N, et al. Allergic Rhinitis and its Impact on Asthma. J Allergy Clin Immunol 2001;108:S147-334.

10. WHO strategy for prevention and control of chronic respiratory diseases. WHO/MNC/CRA/02.1. Geneva: World Health Organization, 2002:9.

11. Prevention and Control of Chronic Respiratory Diseases in low and middle income African countries: a preliminary report. WHO/NMH/CRA/04.1, Geneva: World Health Organization, 2003:22.

12. Ottmani SE, Scherpbier R, Pio A, et al. Practical Approach to Lung Health (PAL). A primary health care strategy for the integrated management of respiratory conditions in people of five years of age and over. WHO/HTM/ TB/2005.351, WHO/NMH/CHP/CPM/CRA/05.3, 2005:15.

13. Prevention and Control of Chronic Respiratory Diseases at country level - towards a Global Alliance against Chronic Respiratory Diseases. WHO/NMH/CHP/ CRA/05.1, Geneva: World Health Organization, 2005:27.

14. WHO meetings of the Global Alliance against Chronic Respiratory Diseases (GARD). GARD General Meeting of 28-29 March 2006 in Beijing, China. Available online: www.who.int/entity/gard/news_events/news/GARD_ Launch_Beijing/en/

15. Bousquet J, Khaltaev N. Global surveillance, prevention and control of chronic respiratory diseases. A comprehensive approach. Geneva: World Health Organization, 2007:146.

16. Global Alliance against Chronic Respiratory Diseases Action Plan 2008-2013. Geneva: World Health Organization, 2008:28.

17. 2008-2013 Action Plan for the Global Strategy for the Prevention and Control of Noncommunicable Diseases. Geneva: World Health Organization, 2008:48.

18. WHO Global Alliance against Chronic Respiratory Diseases-World Health Organization. Available online: http://www.who.int/gard/en/

19. UN Political Declaration of the High-level Meeting of the General Assembly on the Prevention and Control of Non-communicable Diseases 66/2 3rd plenary meeting 19 September 2011. Available online: www.who.int/nmh/ events/un_ncd_summit2011/en/

20. Global Action Plan for the Prevention and Control of Noncommunicable Diseases 2013-2020. Geneva: World Health Organization, 2013:103.

21. Yorgancioglu A, Cruz AA, Bousquet J, et al. The Global Alliance against Respiratory Diseases (GARD) Country Report. Prim Care Respir J 2014;23:98-101.

22. Noncommunicable Diseases Country Profiles 2011. Geneva: World Health Organization, 2011:209.

23. Noncommunicable Diseases Country Profiles 2014. Geneva: World Health Organization, 2014:209.

24. Global Health Estimates 2015. Deaths by Cause, Age, Sex, by Country and Region, 2000-2015, Geneva, World Health Organization 2016. Available online: http://www. who.int/healthinfo/global_burden_disease/estimates/en/ index1.html

25. Yorgancioglu A, Calderon MA, Cruz A, et al. The Global Alliance against Respiratory Diseases (GARD). Interim Report 2016. Available online: www.who.int/gard/GARD_ country_report_2016.pdf?ua=1

26. Sepúlveda R. Chile: Chile's de-medicalised programme for ACRD at the primary care level: Impact on asthma control. The Global Asthma Report 2011. The International Union against Tuberculosis and Lung Diseases. Paris, France, 2011.

27. Ottmani SE, Scherpbier R, Chaulet P, et al. Respiratory Care in Primary Care Services- A survey in 9 countries. WHO/HTM/TB, Geneva: World Health Organization, 2004:107.

28. European Lung White Book, Sheffield, European Respiratory Society, 2013. Available online: http://www. erswhitebook.org

29. WHO Report on the global tobacco epidemic 2017. Tobacco control country profiles. Available online: www. who.int/tobacco/about/vision/en

30. Laurendi G, Mele S, Centanni S, et al. Global alliance against chronic respiratory diseases in Italy (GARD-Italy): strategy and activities. Respir Med 2012;106:1-8.

31. $2015 / 2016$ Year of SEPAR. European Respiratory Journal. Available online: http://www.ersnet.org/the-society/news/ year-of-separ

32. Nissinen A, Berrios X, Puska P. Community-based noncommunicable disease interventions: lessons from 
developed countries for developing ones. Bull World Health Organ 2001;79:963-70.

33. Haahtela T, Tuomisto LE, Pietinalho A, et al. A 10 year asthma programme in Finland: major change for the better. Thorax. 2006;61:663-70.

34. Haahtela T, von Hertzen L, Mäkelä M, et al. Finnish Allergy Programme 2008-2018--time to act and change the course. Allergy 2008;63:634-45.

35. Kinnula VL, Vasankari T, Kontula E, et al. The 10-

Cite this article as: Khaltaev N. GARD, a new way to battle with chronic respiratory diseases, from disease oriented programmes to global partnership. J Thorac Dis 2017;9(11):4676-4689. doi: 10.21037/jtd.2017.11.91 year COPD Programme in Finland: effects on quality of diagnosis, smoking, prevalence, hospital admissions and mortality. Prim Care Respir J 2011;20:178-83.

36. Prevention and Control of Noncommunicable Diseases: Guidelines for primary health care in low-resource settings. Geneva: World Health Organization, 2012:68.

37. Sustainable Development Goals-United Nations 2015. Available online: www.un.org/sustainabledevelopment 